\title{
A ARTE NO COTIDIANO DA INTERAÇÃO À DIMENSÃo ESTÉTICA TERRITORIAL
}

\section{ART IN EVERYDAY INTERACTION TO TERRITORIAL AESTHETIC DIMENSION}

\author{
Fábio Rodrigo de Moraes Xavier ${ }^{1}$
}

\begin{abstract}
Resumo: Neste estudo, nós apresentamos o entendimento com relação à arte no cotidiano da interação à dimensão estética territorial. Será colocado, por meio do entendimento da arte, como processo generalizado do cotidiano que se movimenta pela interação, e como isso promove o sentir em comum como processo estético que desencadeia o condicionamento mental na condição territorial. Dentro dessa perspectiva, pode-se chegar à ideia da Geo-Filosofia, bem como o condicionamento do sentido e sua configuração.
\end{abstract}

Palavras-chave: Arte; estética; território.

\begin{abstract}
The study, we present the understanding regarding art in the daily interaction with the territorial aesthetic dimension. The understanding of art, as a generalized everyday process that through interaction, it promotes feeling in common as aesthetic process that triggers mental conditioning in the territorial condition. Within this perspective, one can arrive at the idea of Geo-Philosophy, the conditioning of meaning.
\end{abstract}

Keywords: Art; aesthetic; territory.

\section{Introdução}

A arte no cotidiano da interação à dimensão estética territorial desenvolve-se na ligação entre pessoas, na articulação existencial dentro da realidade. Esse movimento conduz acontecimentos que proporcionam a lógica do sentido na construção significativa do sujeito.

O objetivo deste artigo é compreender a arte no cotidiano como arte generalizada que se encontra no estar-junto com outro como processo interacional, a estética que constitui condução significativa e produz território. Isso se desenvolve em acontecimentos do cotidiano que permeia o mundo do sujeito à condução do conhecimento e a Geo-Filosofia.

A indagação central da nossa investigação diz respeito de que modo essa arte conduz o acontecimento existencial do ser, como constitui a construção significativa na lógica do sentido do indivíduo. A percepção do acontecimento que proporciona envolvimento no cotidiano do sujeito na produtividade da realidade.

Para alcançar o nosso intuito, baseamo-nos em Maffesoli (1996) na reflexão da arte generalizada no estar-junto com o outro, também em Simmel (1983) na perspectiva de interação e Schutz (2012) na percepção da intersubjetividade. Isso proporciona entender o envolvimento do indivíduo como se constrói na ligação entre pessoas na condição situacional do cotidiano.

No que concerne a dimensão estética territorial nós temos Gilles Deleuze, com o entendimento da terra e a territorialidade do mundo do ser, como a lógica do sentido e acontecimentos. Isso permite entender a produtividade mental como ligação existencial entre pessoas, assim como a observação do movimento cotidiano na percepção do conhecimento.

A nossa justificativa é entender a movimentação do cotidiano como processo de interação situacional do sujeito ligado à arte, também a condução do conhecimento como aspecto de afetação,

\footnotetext{
${ }^{1}$ Universidade Federal do Pará, PA, Brasil.
} 
algo que constitui como território. A ligação entre pessoas como na produtividade existencial do mundo, que envolve a lógica de configuração de sentido no cotidiano que nos cerca.

\section{A arte no cotidiano da interação}

Para o entendimento da arte como processo cotidiano da interação, nós observamos a expressividade das pessoas que adentram a produtividade situacional na condição social. Onde se caracteriza em forma de mentalidade e desenvolve a composição estética como processo mundano territorial a produtividade da realidade.

Tais são justamente os elementos, inseparáveis na realidade de cada ser e acontecer sociais: um interesse, um fim, um motivo e uma forma ou maneira de interação entre indivíduos, pelo qual ou em cuja figura aquele conteúdo alcança a realidade social. (SIMMEL, 1983, p. 61)

A interação contribui para articulação entre pessoas no cotidiano, na produtividade que envolve a condução do real. Isso se evidencia por conta de processos intersubjetivos (SCHUTZ, 2012), o mundo a qual o indivíduo participa, nisso nós observamos o conteúdo que alcança a realidade como mundo sociocultural.

Vamos partir de um exame de articulações e formas de organizações do mundo social que constituem a realidade social das pessoas que nele vivem. A pessoa nasce num mundo que existia antes de seu nascimento e que, logo de partida, não é um mundo simplesmente físico, mas também um mundo sócio-cultural. Esse último é um mundo pré-constituído e pré-organizado, cuja a estrutura especial é resultado de um processo histórico e diferente, portanto, em cada cultura ou sociedade. (SCHUTZ, 2012, p. 79).

As articulações de organizações desenvolvem-se pela interação, a pessoa conduz o contato com a realidade e disso nós entendemos a imanência do tempo, as estruturas organizacionais que interferem no modo como o indivíduo compõe o seu mundo e significado. Um movimento de apreensão na logística de organização do conhecimento no cotidiano "certos traços, contudo, são comuns a todos os mundos sociais porque enraízam-se na condição humana" (SCHUTZ, 2012, p. 79), ou seja, nós observamos as virtualidades e acontecimentos que a condição humana constitui.

O que é a imanência? uma vida... Ninguém melhor que Dickens narrou o que é uma vida, ao considerar o artigo indefinido como índice do transcendental. Um canalha, um mal sujeito, desprezado por todos, está para morrer e eis que aqueles que cuidam dele manifestam uma espécie de solicitude, de respeito, de amor, pelo menor sinal de vida do moribundo [...] Uma vida não contém nada mais do que virtuais. Ela é feita de virtualidades, acontecimentos, singularidades. (DELEUZE, 1995, p 5-6)

As singularidades evidenciam a produtividade de diferentes pessoas e de acontecimentos que constroem virtualidades "Não são qualidades e propriedades físicas, mas atributos lógicos ou dialéticos. Não são coisas ou estados de coisas, mas acontecimentos.", relata (DELEUZE, 1974, p. 5). A condução da interação na lógica existencial constitui a realidade, nós observamos os acontecimentos como produto da movimentação e o conhecimento se desenvolve com a vida do cotidiano, a interação nos processos intersubjetivos do mundo organizado, a educação do indivíduo como condição humana que se articula no espaço e no tempo. 
A psicologia do espírito é uma psicologia da idéia, dos elementos simples ou dos mínima, dos indivisíveis: ela ocupa, essencialmente, a segunda parte do sistema do entendimento, "as idéias de espaço e de tempo". É o atomismo. Por outro lado, a psicologia da natureza humana é uma psicologia das tendências, ou, antes, até mesmo uma antropologia, uma ciência da prática e, sobretudo, da moral, da política e da história; finalmente, uma verdadeira crítica da psicologia, pois ela encontra a realidade do seu objeto dado em todas as determinações que não são dadas em uma idéia, em todas as qualidades que ultrapassam o espírito. (DELEUZE, 2001, p. 10)

Nessa perspectiva de psicologia é importante entender que a pessoa desenvolve interações e conduz a realidade e significado de mundo, o movimento o acontecimento que conduz ideias e organizações do espaço e tempo daquele que interage na realidade. Nós entendemos nessa psicologia prática como pragmática no cotidiano e, consequentemente, "é no sentido de que a relação necessária é o espírito como afetado, como determinado (em certas circunstâncias) a formar pela idéia de um objeto a idéia de um outro objeto.", menciona (DELEUZE, 2001, p. 13).

Essa lógica do sentido da relação e da afetação é que nós observamos a interação da arte no cotidiano, como processo que permeia acontecimentos e fatores significativos. A organização da realidade que é conduzida pela lógica do sentido possui interesses do indivíduo, como interação e produtividade do mundo que circunda a pessoa, a qual expressa significado da realidade.

O interesse como interação entre indivíduos compõe de expressividade da arte que é produzida no cotidiano. Isso compõe o envolvimento que "É, portanto, a partir de uma arte generalizada que se pode compreender a estética como faculdade de sentir em comum", refere (MAFFESOLI, 1996, p. 28).

Esse sentir em comum pertence à lógica do sentido que evidencia a produtividade da realidade. Isso adentra o acontecimento que pulsa o movimento entre pessoas e seus efeitos na condução do cotidiano.

Todos os corpos são causas uns para os outros, uns com relação aos outros, mas de que? São causas de certas coisas de uma natureza completamente diferente. Estes efeitos não são corpos, mas, propriamente falando, "incorporais". Não são qualidades e propriedades físicas, mas atributos lógicos ou dialéticos. Não são coisas ou estados de coisas, mas acontecimentos. Não se pode dizer que existam, mas, antes, que subsistem ou insistem, tendo este mínima de ser que convém ao que não é uma coisa, entidade não existente. (DELEUZE, 1974, p. 5)

Isso pertence ao movimento situacional entre pessoas e pode se "desvelar a partir das afecções é a ideia dessa subjetividade. A palavra ideia já não pode ter o mesmo sentido. A psicologia das afecções será a filosofia de um sujeito constituído.”, cita (DELEUZE, 2001, p. 13). Nós observamos essa arte generalizada, que é a estruturação da psicologia das afecções, como processo ligado à interação na condução do cotidiano e ela se caracteriza como aspecto significante da realidade.

Pois o presente vivo e a extensão temporal que acompanha o ato, que exprime e mede a ação do agente, a paixão do paciente. Mas, na medida da unidade dos corpos entre si, na medida da unidade do princípio ativo e do princípio passivo, um presente cósmico envolve o universo inteiro: só os corpos existem no espaço e só o presente no tempo. (DELEUZE, 1974, p. 5) 
O presente vivo representa os diversos tipos interacionais que desenvolve como fator intersubjetivo à condição do estar-junto com outro e constrói a arte generalizada no cotidiano. A estética permeia a pessoa dentro do tempo de existência e proporciona o espaço situacional entre os que participam do movimento interacional dentro da realidade cotidiana.

Nós observamos com isso o presente cósmico que Deleuze (1974) ressalta como rede de relacionamentos e unidade do mundo que constitui sistemas e singularidades entre pessoas. $\mathrm{O}$ cotidiano como a condução da realidade da arte dentro das interações e o movimento de um tempo e espaço presente. Um sistema que constitui o conhecimento como sentido e significado com relação ao contato entre indivíduos.

Um mundo envolve já um sistema infinito de singularidades selecionadas por convergência. Mas, neste mundo, constituem-se indivíduos que selecionam e envolvem um número finito de singularidades do sistema, que as combinam com aquelas que seu próprio corpo encarna, que as estendem sobre suas próprias linhas ordinárias e mesmo são capazes de reformá-las sobre as membranas que colocam em contacto o interior e o exterior. (DELEUZE, 1974, p. 113).

O sistema infinito são formas de interação que as pessoas articulam ao movimento significativo, o envolvimento do sujeito no processo contínuo de conhecimento à produção temporal espacial da arte no cotidiano da interação, "A essência e o destino do empirismo não estão ligados ao átomo, mas à Associação" (DELEUZE, 2001, p. 15). Essa associação salienta ligação à condição do sentido dentro da realidade, o envolvimento do ser e a produtividade do mundo presente.

A arte na interação do cotidiano é desenvolvida no acontecer na movimentação da realidade, como se observa a arte no estar-junto com outro, a produtividade de sentido que permeia as pessoas. Nisso observa-se a condução de espaço e tempo que tem conexão de sistemas de redes de construções e associações ao movimento entre indivíduos.

Assim, nós podemos examinar a percepção dessa arte no cotidiano da interação como processo de produção da dimensão estética territorial, já que essa produtividade se caracteriza na formação de movimentos entre pessoas e influências situacionais na condução cotidiana, isso serve de alicerce para observar a lógica do sentido, o território como fonte mental de construção da realidade. A corporeidade como aspecto situacional de expressividade na lógica do conhecimento à movimentação do indivíduo no cotidiano.

\section{A dimensão estética territorial}

A dimensão estética territorial constitui-se na interação à arte generalizada do cotidiano entre pessoas e na produtividade das relações, na composição social e de estruturação real do cotidiano. Isso atende pela "natureza dos acontecimentos aos quais seus conceitos nos convocam, ou que ela nos torna capazes de depurar em conceitos", relatam (DELEUZE; GUATTARI, 1992, p. 47).

Nesse contexto, nós observarmos a arte generalizada de Maffesoli (1996) na atuação de como movimento interacional entre pessoas produz sensações na produtividade estética do sentir em comum. Isso atende para "Pensar não é nem um fio estendido entre um sujeito e um objeto, nem uma revolução de um em torno do outro. Pensar se faz antes na relação entre o território e a terra", argumentam (DELEUZE; GUATTARI, 1992, p. 111).

A terra encontra-se na disposição do sentido e condiciona pessoas no sentir em comum na relação de sensações, também na produtividade da interação entre sujeitos na Geo-Filosofia. Essa dimensão estética territorial promove movimentos contínuos "a sociedade não é uma substância concreta, mas um processo da associação, isto é, um processo contínuo e criador de 
interações", expõe (VANDENBERGUE, 2005, p. 77), a qual alcança a condução da realidade como ela se estrutura.

Como se nós estivéssemos em movimentação com a afetação e o conhecimento se revelam como processos situacionais da realidade, isso se realiza em "sistemas de signos e de símbolos com sua estrutura de significados particular, de formas institucionalizadas de organização social, de sistemas de status e prestígio, etc.”, apresenta (SCHUTZ, 2012, p. 80). Nessa perspectiva, nós observamos que a terra e o território "não cessam de um movimento de desterritorialização in loco, pelo qual ultrapassa todo território", explicam (DELEUZE; GUATTARI, 1992, p. 111).

Esse território se notabiliza na lógica do sentido e é desenvolvido pelo sujeito na movimentação interacional no cotidiano, na construção do conhecimento, no contato com a terra que expressa significado situacional mental. Isso envolve o território à condução da realidade e ao cotidiano do indivíduo.

A inerência dos motivos psico-históricos e materiais caracteriza-se como intrínseca ao fenômeno da compressão considerado em sua totalidade. O desenvolvimento, psiquicamente real, de uma cadeia articulada e constituída de elementos consolidados em sua sequência temporal a nós se torna compreensível unicamente por força da relação objetiva e transvital de seus conteúdos. Sem constatar a existência da ascensão e decadência que nela se manifesta e sem saber que os conteúdos, objetivamente e como tais, estabelecem, entre si, uma referência recíproca, bem como saber ainda que, independente de sua realização no tempo, cada um deles fundamenta ou determina o outro, também não é possível compreendê-los como sequência psíquica temporalmente real. Por outro lado, como desenvolvimento ordenado, esta determinação ideal entre os mesmos se estabelece, é possível na medida em que um movimento psíquico contínuo os atravessa. (SIMMEL, 1983, p. 87).

Esse envolvimento com a realidade apresenta o processo psico-histórico, a condução de rede de sentido e a movimentação de significado como construção da realidade do indivíduo. Isso evidencia o desenvolvimento ordenado da estrutura situacional da pessoa que se estabelece nos primeiros anos de vida. A criança quando constrói a realidade entra em contato com diversos tipos de estruturas significativas e ela conduz à movimentação do sentido com relação ao mundo que a cerca.

A criança não para de dizer o que faz ou tenta fazer: explorar os meios, por trajetos dinâmicos, e traçar o mapa correspondente. Os mapas dos trajetos são essenciais à atividade psíquica. $\mathrm{O}$ que o pequeno Hans reivindica é sair do apartamento familiar para passar a noite na vizinha e regressar na manhã seguinte: o imóvel como meio. Ou então: sair do imóvel para ir ao restaurante encontrar a menininha rica, passando pelo entreposto de cavalos - a rua como meio. (DELEUZE, 1997, p. 73).

Isso compõe de produção de trajetos significativos na atividade psíquica daquele ser, a afetação, o estar-junto com o outro, a organização do sentido que produz a dimensão estética territorial "- Ser, de um pensamento - Natureza com movimentos diagramáticos infinitos. Pensar consiste em estender um plano de imanência que absorve a terra", comentam (DELEUZE; GUATTARI, 1992, p. 117). A Geo-Filosofia desenvolve-se na corporeidade e é produzida na movimentação entre sujeitos, nós entendemos, com isso, que a dimensão estética territorial é esquema de articulação ao mundo do ser.

Nesse sentido, nós temos a condição do pensamento como articulação situacional que permeia a realidade, também a imanência como condução do sentido no cotidiano do indivíduo. A pessoa absorve movimentação situacional e produz conhecimento na articulação de significado à linguagem. 
"Entre estes acontecimentos-efeitos e a linguagem ou mesmo a possibilidade da linguagem, há uma relação essencial: e próprio aos acontecimentos o fato de serem expressos", diz (DELEUZE, 1974, p. 13), ou seja, os acontecimentos como movimentação existencial à condução do ser.

Com isso, nós observamos que o sentido é o resultado da dimensão estética territorial, como processo de construção do cotidiano e envolvimento significativo. Nessa perspectiva, nós temos os costumes que "Constituem a herança social que é transmitida às crianças que nascem e crescem dentro do grupo", refere (SCHUTZ, 2012, p. 80), e caracteriza redes significativas na interação. "Isso é assim porque o sistema de costumes estabelece um padrão em termos do qual o grupo interno 'define a sua situação'. Mais que isso: originado de situações anteriores, definidas pelo grupo, o código de interpretação”, continua (SCHUTZ, 2012, p. 80), então:

O sentido está sempre pressuposto desde que o eu começa a fala; eu não poderia começar sem esta pressuposição. Por outras palavras: nunca digo o sentido daquilo que digo. Mas, em compensação, posso sempre tomar o sentido do que digo como objeto de uma outra proposição, da qual, por sua vez, não digo o sentido. Entro então em uma regressão infinita do pressuposto. Esta regressão dá testemunho, ao mesmo tempo, da maior impotência daquele que fala e da mais alta potência da linguagem: minha impotência em dizer o sentido do que digo, em dizer ao mesmo tempo alguma coisa e seu sentido, mas também o poder infinito da linguagem de falar sobre as palavras. (DELEUZE, 1974, p. 31).

A preposição do sentido ressalta situações históricas, a condição da linguagem como utilização ao mundo que cerca a pessoa. Além disso, o sistema de significado que envolve o sujeito e constitui a estética territorial na condução da realidade, em que a pessoa precisa se adequar para que possa conviver de forma "harmônica" na movimentação da realidade. Essa adequação à repetição que o sujeito precisa seguir é o que caracteriza a regressão, mas muito mais que isso "A cabeça é o órgão das trocas, mas o coração é o órgão amoroso da repetição", esclarece (DELEUZE, 1988, p. 11-12), essa ideia nos faz entender a relação do território situacional do indivíduo e a expressividade de sua estética na condução do cotidiano.

Repetir é comportar-se, mas em relação a algo único ou singular, algo que não tem semelhante ou equivalente. Como conduta externa, esta repetição talvez seja o eco de uma vibração mais secreta, de uma repetição interior e mais profunda no singular que a anima. A festa não tem outro paradoxo aparente: repetir um “irrecomeçável". Não acrescentar uma segunda e uma terceira vez à primeira, mas elevar a primeira vez à "enésima" potência. Sob esta relação da potência, a repetição se reverte, interiorizando-se. (DELEUZE, 1988, p. 11)

Desse modo, é possível observar a relação do único singular que é o indivíduo que adentra o mundo cotidiano na interação com outras pessoas, a internalização da repetição de diferentes construções estéticas territoriais. Isso envolve a condição do conhecimento individual como movimento intersubjetivo (SCHUTZ, 2012), o mundo que o sujeito constrói, mas, além disso, isso envolve impulsos e propósitos para a condução interacional.

Interação sempre surge com base em certos impulsos ou em função de certos propósitos. Os instintos eróticos, os interesses objetivos, os impulsos religiosos e propósitos de defesa ou ataque, de ganho ou jogo, de auxílio ou instrução, e incontáveis outros, fazem com que o homem viva com outros homens, aja por eles, com eles, contra eles, organizando desse modo, reciprocamente, as suas condições (SIMMEL, 1983, p. 165-166). 
Condições que constituem esse desenvolvimento estético territorial com a produtividade significativa no cotidiano, como organização e movimentação do sentido na construção da realidade. A arte no cotidiano da interação como produtividade mental permeia diversos acontecimentos, como também proporciona um estar-junto com o outro como fonte estética. Isso promove a formatação da realidade como processo de envolvimento do ser em aspectos intersubjetivos, nós observamos com isso esse homem cercado de vivência com o outro na ligação de um mundo estruturado.

Assim, a arte generalizada compõe de condutibilidade do estar-junto com outro que desenvolve o mundo, as construções significantes que se movimentam pela interação do cotidiano. Esses acontecimentos colaboram para o conhecimento do sujeito que adentra as estruturas e a dimensão estética territorial, isso se entende como a condição do sentido que condiciona o envolvimento das sensações em movimentos situacionais das pessoas na realidade.

A isso nós entendemos a arte no cotidiano como processo de ligação entre pessoas que conduzem sentido de configuração real do sujeito, além disso, a produtividade de conhecimento situacional com relação ao mundo que o cerca. Essa perspectiva nos faz pensar no movimento dos acontecimentos como estruturas que vão condicionando sentido de mundo, a constituição do ser como fonte de produtividade situacional com relação ao outro.

Isso nada mais é que pensar os acontecimentos do cotidiano como processos que constituem a pessoa, o conhecimento que se desenvolve na expressividade íntima do indivíduo e se articula como fatores simbólicos na interação do cotidiano. O corpo que envolve o ser na produtividade de conduzir a vida dentro de um mundo articulado com redes de territórios mentais que nós conduzimos a uma realidade existente e presente.

\section{Considerações finais}

$\mathrm{O}$ artigo procura observar de que modo a arte no cotidiano da interação se desenvolve dentro da estética territorial, a maneira de como o sentido entre pessoas se constitui dentro do envolvimento situacional do cotidiano. Isso proporciona a observação na movimentação do sujeito dentro do processo interacional, o conhecimento como produtividade existencial no envolvimento significativo simbólico à ligação com o outro.

No primeiro momento, nós observamos a arte no cotidiano como a arte generalizada, o sentir-junto com outro que se desenvolve como processo interacional na produtividade da realidade. Isso demonstra processos intersubjetivos que articula organizações do mundo. Nisso nós percebemos a imanência os acontecimentos que circunda o sujeito dentro da virtualidade em configurações situacionais que se observa na psicologia prática.

A lógica do sentido constitui-se nesse movimento de organizações de tempo e espaço que vai produzindo o cotidiano da pessoa, como na relação de afetação que envolve o estarjunto e interações dentro da realidade do indivíduo. Isso envolve rede de significado e adentra a produtividade mental do conhecimento do sujeito e destaca sistemas de significado que permeiam o pensamento do sujeito na condução da realidade como esquema de construções territoriais mentais do ser.

No segundo momento, nós entendemos que a dimensão estética territorial possui a arte generalizada, o estar-junto com o outro em fatores interacionais do cotidiano. Nós observamos com isso, a terra como configuração situacional do sujeito que articula processos territoriais significativos da realidade, como a condução de esquemas de sentido que é produzida nos acontecimentos do cotidiano. Dessa forma, nós podemos observar a condição psico-histórica de estruturas do ser que circunda a realidade situacional e processa o movimento da Geo-Filosofia. 
Assim, nós temos os acontecimentos e os efeitos da linguagem como processo de conhecimento significativo da pessoa dentro do movimento cotidiano, sendo esse processo de articulação com a condução de sentido como forma de construção real. A lógica do sentido é fonte de articulação e condução de ordem mental do ser, isso configura a produtividade de conhecimento dentro do cotidiano. O resultado da dimensão estética territorial se constitui no envolvimento da construção significativa.

A arte no cotidiano da interação e a dimensão estética territorial se desenvolvem na interação entre pessoas, o que configura a construção da realidade dentro de diferentes acontecimentos e movimento situacional do sujeito. Isso proporciona o condicionamento da estruturação do conhecimento como modo de articulação de redes de sentido ao envolvimento da pessoa dentro do mundo que a cerca e na sua existência habitual.

\section{Referências}

DELEUZE, G. GUATTARI, Félix. O que é a Filosofia? Tradução de Bento Prado Jr. e Alberto Alonso Muñoz. Rio de Janeiro: Ed. 34, 1992.

DELEUZE, G. Lógica do Sentido. Tradução: Luiz Roberto Salinas Fortes. São Paulo: Perspectiva; Ed. da Universidade de São Paulo, 1974.

DELEUZE, G. Empirismo e subjetividade: ensaio sobre a natureza humana segundo Hume. Tradução de Luiz B. L. Orlandi. São Paulo: Ed. 34, 2001.

DELEUZE, G. L’Immanence: une vie... Philosophie, n. 47. Paris: Les Éditions de Minuit, $1^{\circ}$ de setembro de 1995, p. 5-6. Cito na tradução de Tomaz Tadeu, Revista Educação \& Realidade, v. 27, n. 2 , p. 10-18, 2002.

DELEUZE, G. Diferença e repetição. Tradução de Luiz Orlandi e Roberto Machado. Rio de Janeiro: Graal, 1988.

DELEUZE, G. Crítica e clínica. Tradução de Peter Pal Pelbart. São Paulo: Ed. 34, 1997

MAFFESOLI, M. No fundo das aparências. Tradução de Bertha Halpern Gurovitz. Petrópolis: Vozes, 1996.

SCHUTZ, A. Sobre a fenomenologia e relações sociais. Tradução de Ângela Melin. Petrópolis: Vozes, 2012.

SIMMEL, G. O problema da sociologia. Tradução de Carlos Alberto Pavanelli. São Paulo: Ática, 1983.

VANDENBERGUE, F. As sociologias de Georg Simmel. Belém: Ed. Universitária UFPA, 2005.

\section{Sobre o autor}

Fábio Rodrigo de Moraes Xavier. Atualmente no mestrado do Programa de Pós-Graduação em Comunicação, Cultura e Amazônia (PPGCOM/UFPA) na linha de pesquisa Comunicação, Cultura e Socialidades na Amazônia. Fez parte do corpo discente da Universidade Federal do 
Pará (UFPA) no curso de Bacharelado em Comunicação Social - Jornalismo (2014 - 2018). Foi bolsista de Iniciação Científica (PIBIC) no projeto de pesquisa a Experiência social, cultura e comunicação na Amazônia. Etapa 1: intersubjetividade e pragmática comunicativa em mercados de Belém, financiado pelo Conselho Nacional de Desenvolvimento Científico e Tecnológico (CNPQ) e também bolsista de Iniciação Científica (PIBIC) no projeto de pesquisa A dimensão intersubjetiva dos fenômenos comunicativos. Elementos teóricos e metodológicos para pensar a Comunicação a parti da noção de intersubjetividade financiado pelo Conselho Nacional de Desenvolvimento Científico e Tecnológico (CNPQ). Nas Iniciações Científicas fez parte do Grupo de Pesquisa Fenomenologia da Cultura e da Comunicação. Foi também discente do curso de Licenciatura em Geografia da Universidade do Estado do Pará (UEPA) no ano de (2013). Possui como temática a fenomenologia, hermenêutica e intersubjetividade à etnografia, etnometodologia na perspectiva cultural das socialidades.

E-mail: fabio.rodrigo.moraes.xavier@gmail.com. 